\title{
In this issue
}

\author{
Richard Strange ${ }^{1}$
}

Published online: 26 April 2017

(C) Springer Science+Business Media Dordrecht and International Society for Plant Pathology 2017

This issue of Food Security consists of 15 original papers and three book reviews. As always, the question is: are there any common themes that allow papers to be grouped together? In this issue there seem to me to be four themes: are we currently making the best use of the resources available (5 papers)? How have political situations affected food security (2 papers)? What is the capacity for adaptation to climatic events (2 papers)? What are the impacts of various projects designed to improve productivity ( 5 papers)? The final paper concerns the benefits of school gardens.

Paul Watts and co-authors examined the food security of the Inuit in Canada. They combined fish and marine mammal records for the calendar year 2008, which allowed them to calculate marine ecological footprints. Findings showed that, in some communities, the caloric catch may amount to as much as $40 \%$ of their basal metabolic requirements. For such an important source of food, the authors make a plea for the inclusion of traditional Inuit knowledge through university food security programs.

Martin Browne and co-authors report that the inhabitants of Timor-Leste have Christian and older animist beliefs and spend considerable time and resources on rituals associated with them. These centre around marriages and deaths but many are also related to food production. However, the authors found that these did not stifle innovation in cropping but rather contributed to the social capital required for crop production and food security in the country.

Richard Strange

r.strange@ucl.ac.uk

1 Department of Genetics, Evolution and Environment, University College London, Gower Street, London WC1E 6BT, UK
In their study of fruit production and consumption in Western Kenya, Gudrun Keding and co-authors found that $80 \%$ of women did not achieve the recommended amount of $200 \mathrm{~g}$ of fruits per day and had low vitamin A and C intakes. Two factors limiting diets were taboos and a negative view of wild fruits, often regarded in Kenya as "poor man's food" or "children's food".

Mohamed Alemu and co-authors point out that insects have the potential for making a sustainable contribution to food security. They found that products with medium amounts $(5 \%)$ of cricket flour were preferred to those with none or greater amounts $(10 \%)$ and predicted that buns made with cricket flour are likely to have a greater market share than standard buns. Also, as there was a demand for bread made with cricket flour, this likely to become available in Kenya.

Fertile land lost to cultivation by expansion of cities and for other reasons is a problem in China and newly cultivated land is not as productive. Xinliang $\mathrm{Xu}$ and co-authors studied the impact of these factors during 1990 to 2010 employing land use data and the Global Agro-ecological Zones (GAEZ) model. They found that total production productivity decreased despite an increase in the area of cultivated land.

In the first of the two papers concerned with the politics of food security, Derrill Watson, who is the newly appointed Senior Editor for papers dealing with the economics and politics of food security, examines the political economy of food price policy during the global food price crisis of 2006-2008. He found, in a study 13 countries, that governments focused predominantly on consumer and trade policies rather than the more expensive option of increasing production. Decisionmaking by a single body (unitary) on the basis of maximizing social welfare was the best option rather than fragmented decision-making by many bodies or decision making on a self-interest basis, whether unitary or fragmented. 
Eckart Woertz reviews the food security situation in Iraq, which has been profoundly affected by its oil-based economy, three decades of conflict and authoritarian rentierism. One startling factor is that the Iraqi Public Distribution System is the world's largest food programme. In a 6month online survey during 2015 and involving 152 Iraqi experts from academia, ministries and NGOs found that the major challenges to food security were political instability and poor governance. While these conditions persist, the author concludes that purely technocratic policies are unlikely to improve food security.

In the first of the two papers on the capacity to adapt to climate events, Taoyuan Wei and co-authors examined the role of autonomous adaptation by farmers and adaptation through markets to three extreme weather scenarios using a computable general equilibrium model. At the national level, impacts of extreme precipitation were not serious, with the harvest of maize, the most affected crop, being reduced by $4 \%$ without adaptation and $1 \%$ with adaptation. At the provincial level, however, impacts may be grave and become even worse with adaptation.

Christian Thierfelder and co-authors ask the question, how climate smart is conservation agriculture (CA)? They state that for a cropping system to qualify as climate-smart it has to deliver three benefits: a) adaptation to the effects of climate and increased resilience; b) mitigation of climate effects by sequestering carbon $(\mathrm{C})$ and reducing greenhouse gas emissions (GHG); and c) increase productivity and income sustainably. Working in Southern Africa, they found that results were generally positive in terms of conservation of soil moisture, which is beneficial in overcoming seasonal dry spells, and in increasing productivity and profitability. However, there was a lag period of $2-5$ years before these benefits were realized, although in some cropping systems there was an immediate economic benefit in terms of reduced labour requirements.

Coming now to the first of the five papers reporting on the results obtained from projects designed to improve productivity, Joseph Kangmennnaang and co-authors tested the effects of a participatory agroecological development project on household wealth and food security in Malawi over a 2 year period. This involved encouragement of experimentation, community involvement, and farmer-to-farmer teaching of agroecology, nutrition and gender equity. Even over this comparatively short period, the project was a success with a significant increase in household wealth and considerable reductions in food insecurity.

Bashir Jama and co-authors determined the yield response, nitrogen use efficiency and financial returns to fertilizer use on smallholder farms in four countries of Southern Africa, Malawi, Mozambique, Zambia and Tanzania. They found that average yields over a total of 940 demonstration sites were $1.6 \mathrm{t} \mathrm{ha}^{-1}$ in the controls, $2.8 \mathrm{t} \mathrm{ha}^{-1}$ where $\leq 50 \%$ of the recommended application rate of nitrogen was applied and $4 \mathrm{t}$ $\mathrm{ha}^{-1}$ where $100 \%$ or more of the recommended rate was applied. They concluded that growing maize without nitrogen fertilizer results in loss of land productivity and profitability, whereas application of $50 \%$ or more of the recommended rate results in substantial increases in yields and profitability. (These results point to the importance of intercropping or relay cropping with nitrogen fixing plants or trees where nitrogenous fertilizer is not available and even where it is owing to their other agroecological benefits. Ed.)

Sweet potato is normally propagated by vines but these are not obtainable in dry areas in the dry seasons but can be grown in swampy areas. Therefore, as a result and as found by Paul Rachkara and co-authors in Uganda, an informal private enterprise system has been set up consisting of vine multipliers, traders, dry season root farmers, transporters and town sellers. The authors contrast this sustainable system with previous sweet potato projects, operated by NGOs or government providing vines for free distribution to farmers. After the projects had terminated, few such schemes thrived for long.

The study by Isaac Gershon and co-authors of yam production in the Zabzugu district of Ghana showed that post-harvest losses were high, averaging 160 USD per farmer per production season. Commercial farmers were less successful at managing these losses than subsistence farmers. The authors therefore suggest that policy interventions should target education and training of farmers in order to improve their skills in managing postharvest losses.

Following on from the wastage of yam, caused by postharvest losses, Ruth Ngadze and co-authors draw attention to the wastage of fruit of the monkey orange tree (Strychnos spp.) in Southern Africa and particularly in Zimbabwe. Here most of the fruit, when in season, lies on the ground unpicked. The authors suggest that this resource, particularly its processed products, should be commercialized, as a survey of smallholder farmers showed that it was extensively used in food and drink and had health benefits.

The final paper by Pepijn Schreinemachers and co-authors evaluates the outcomes and impacts of a school gardening project in Bhutan. They found that when gardening was linked to complementary lessons and promotional activities, including awareness of vegetables and knowledge of sustainable agriculture, preferences of 9-15 year old schoolchildren for healthier foods were considerably increased.

In the first of the book reviews, Barbara Burlingame reviews three books from the International Food Policy Research Institute with the titles Nourishing millions: stories of change in nutrition, 2016 Global Food Policy Report and 2016 Global Nutrition Report, From Promise to Impact: Ending Malnutrition by 2030. Readers of Food Security will find much in these volumes that accentuate the interdependence of agriculture, nutrition and health. I particularly liked the call for agriculture to be 'nutrition driven' rather than 'nutrition sensitive'. 
Peter Scott reviews Global Panel on Agriculture and Food Systems for Nutrition: Food systems and diets: facing the challenges of the twenty-first century. He points out that the chair of the leading experts who undertook much of the work and drafted the report, Lawrence Haddad, is also co-chair of the Independent Expert Group that prepared the 2016 Global Nutrition Report, mentioned above. Peter found the two documents closely related and felt that they should be regarded as mutually complementary.

Malcom Blackie found that Colin Tudge's book 'Six steps back to the land' strongly argues the case for 'enlightened agriculture' and notes, among much else, that two of the major obstacles faced by the poor in the developing world are lack of access to information and lack of financial services. 